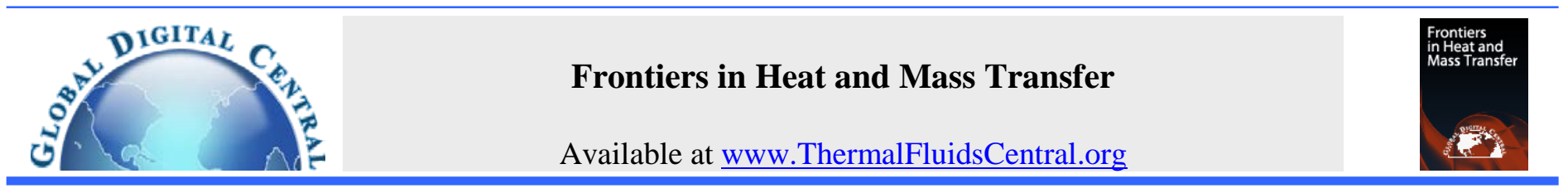

\title{
ASETS-II OSCILLATING HEAT PIPE SPACE FLIGHT EXPERIMENT: THE FIRST SIX MONTHS ON ORBIT
}

\author{
Brenton S. Taft ${ }^{\mathrm{a},}{ }^{*}$ and Kevin W. Irick ${ }^{\mathrm{b}}$ \\ ${ }^{a}$ First U.S. Air Force Research Laboratory, Kirtland Air Force Base, NM, 87117, United States \\ ${ }^{b}$ Applied Technology Associates, Albuquerque, NM, 87123, United States
}

\begin{abstract}
On September 7th, 2017 the U.S. Air Force Research Laboratory launched the second Advanced Structurally Embedded Thermal Spreader (ASETSII) flight experiment to space on Orbital Test Vehicle 5. The ASETS-II experiment is made of three low-mass, low-cost oscillating heat pipes (OHPs) and an electronics/experiment control box. The three primary science objectives of the experiment are to measure the initial on-orbit thermal performance, to measure long duration thermal performance, and to assess any lifetime degradation. The three OHPs on ASETS-II are of varying configuration (center heating with single- and double-sided cooling) and working fluids (butane and R-134a) in order to isolate specific performance parameters of interest. OHP \#3 was specifically designed in order to explore the operating limits on OHP operation in microgravity without requiring excessive operating temperature or pressure. Data collected during the first 6 months of on-orbit operations are presented in this paper. It is shown that each OHP performed as expected, where on-orbit data for OHPs \#1 and \#2 mirrored ground-truth performance, and the OHP \#3 on-orbit maximum operating evaporator temperature increased from ground-truth. The OHPs experienced no significant hysteresis effects and OHP \#1 performed successfully in six-week long continuous operation.
\end{abstract}

Keywords: OHP; Pulsating heat pipe; Microgravity

\section{INTRODUCTION}

Major advances in space-application technologies have led to significant increases in electronic power densities for on-orbit systems. However, development of effective thermal management solutions to mitigate inherent thermal issues from the higher power densities significantly lags that of the heat-generating technologies (Taft 2017). Oscillating heat pipes (OHPs) show promising capabilities in transporting heat rates and in operating under heat densities that far exceed those of most traditional aerospace thermal management solutions.

The OHP was invented in 1990 by Hisateru Akachi and was presented as a continuous loop-type heat pipe filled with a saturated heat transfer fluid (Akachi 1990). The notional OHP, shown in Fig. 1, consists of a closed-loop microchannel with serpentine features. The microchannel is filled with a saturated heat transfer fluid and has three fundamental sections: evaporator, condenser, and adiabatic. Heat is transported from the hotter evaporator section to the colder condenser section through the adiabatic section. In the evaporator section, some of the heat transfer fluid evaporates and expands. In the condenser section, some of the fluid condenses and contracts. The combination of the thermophysical conditions and the serpentine features in the channel causes the formation of vapor plugs and liquid slugs that rapidly oscillate within the channel, resulting in forced-convection-like heat transfer. OHP phenomena and designs have been investigated over the years to accommodate a variety of geometries and sizes for various applications (Ma 2015).

An OHP is a simple, wickless heat pipe capable of rejecting more than 200 times the maximum heat load of an axially grooved heat pipe, and transporting more than 45 times more heat than copper. In addition to outperforming traditional thermal management technologies, OHPs enable low-cost manufacturing techniques due to the lack of an internal wick structure. OHPs provide a low-cost method to alleviate electronics thermal constraints and allow for increased processing power, or bandwidth, for commercial and military users.

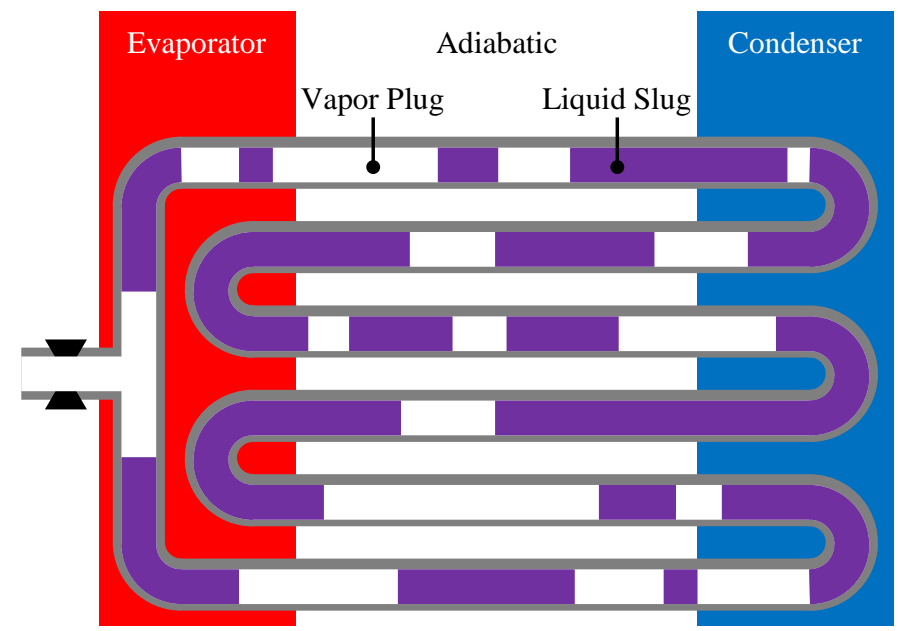

Fig. 1 Notional OHP Diagram

The U.S. Air Force Research Laboratory (AFRL) Space Vehicles Directorate has been investigating OHPs since 2008 (Taft et al. 2012; Taft 2013; Laun and Taft 2014, Smith et al. 2014). In 2012, the original Advanced Structurally Embedded Thermal Spreader (ASETS)

* Corresponding author. Email: AFRL.VSSVOrgMailbox@us.af.mil 
experiment measured the performance of an AFRL-developed OHP aboard a Space Test Program (STP)-funded and NASA-managed microgravity aircraft flight (Taft et al. 2015).

On September $7^{\text {th }}, 2017$ AFRL launched the second Advanced Structurally Embedded Thermal Spreader (ASETS-II) flight experiment to space on Orbital Test Vehicle 5 (OTV-5). OTV-5 is the fifth flight of an $\mathrm{X}$-37B reusable space plane. The $\mathrm{X}$-37B program performs risk reduction, experimentation, and concept of operations development for reusable space vehicle technologies, and is administered by the U.S. Air Force Rapid Capabilities Office (RCO).

The ASETS-II experiment, shown in Fig. 2, is made of three lowmass, low-cost OHPs and an electronics/experiment control box. The three OHPs are of varying configuration (center heating with singleand double-sided cooling) and working fluids (butane and R-134a) in order to isolate specific performance parameters of interest. In addition to serving as a science experiment, the ASETS-II flight experiment serves as a pathfinder for incorporating high performance OHP-based thermal spreaders into flat plate structures such as electronics chip carriers, thermal ground planes and spacecraft panels.

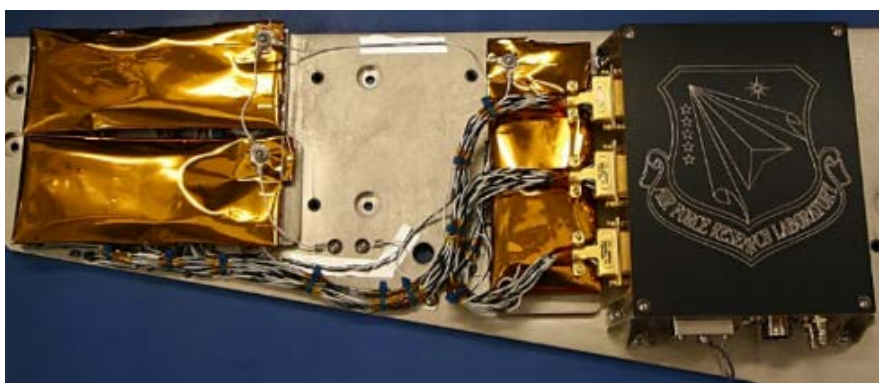

Fig. 2 ASETS-II flight hardware

Microgravity fluid flow, especially two-phase flow, is significantly different than in a terrestrial environment. This is true for steady-state operations, but is more important for transient operation. In addition, the combined effects of the space environment (e.g. thermal cycling, high vacuum, charging, and vibration) are required to verify the performance of the system on orbit for long durations.

The three primary science objectives of the ASETS-II experiment are to measure the initial on-orbit thermal performance, to measure long duration thermal performance, and to assess any lifetime degradation. Flight data is being used to validate microgravity portions of an OHP operating limits model recently published (Drolen and Smoot 2017). Returned flight experiment hardware will be subjected to post-flight testing to assess the presence of any non-condensable gas that may have formed on orbit (Taft 2013).

This paper details the ASETS-II space flight hardware and results collected during the first 6 months on orbit.

\section{EXPERIMENTAL METHOD}

The heart of the ASETS-II Flight hardware, the OHPs, were developed by ThermAvant Technologies under Air Force Contract Number FA9453-13-C-0029. The three OHPs have identical geometries but different boundary conditions and working fluids. The OHPs are embedded in a $2 \mathrm{~mm}$ thick plate and consist of 34 channels in a typical single-layer closed loop design, as shown in Fig. 3. The channels are $1 \mathrm{~mm}$ x $1 \mathrm{~mm}$ with $0.38 \mathrm{~mm}$ thick walls.

A fill ratio of $45 \%$ by mass was targeted for all three OHP designs; fill ratios of $45-47 \%$ were achieved with $\pm 2 \%$ uncertainty. Butane was selected as the working fluid for OHP \#1 and \#2 for its performance stability. R-134a was selected for OHP \#3 in order to explore the Bond number, Bo, limit on OHP operation in microgravity without requiring excessive operating temperature or pressure. Bo is a function of the hydraulic radius of the microchannel, $r$, the acceleration due to gravity, $g$, the fluid surface tension, $\sigma$, and the liquid and vapor mass densities, $\rho_{l}$ and $\rho_{v}$, respectively, given by
$B o=r^{2} g\left(\rho_{l}-\rho_{v}\right) / \sigma$,

which represents the ratio of the body force to surface tension in the fluid.



Fig. 3 Schematic of ASETS-II OHP

Ground testing has shown that OHP \#3 hits an operating limitlikely the swept length, $L_{s}$, limit-between $20 \mathrm{~W}$ and $40 \mathrm{~W}$ of heat input from the small area heater, depending on the condenser temperature (Taft and Smith 2017). In a microgravity environment, the Bo limit should no longer be a factor on OHP operation. Thus, if the flight data, under microgravity conditions, shows limiting behavior similar to that which is seen on the ground, the vapor inertia or $L_{s}$ limit—as opposed to the Bo limit—would likely be causing partial dryout of the OHP. The swept length is defined as

$L_{s}=U / f$,

with $U$ and $f$ are the fluid velocity and nucleation frequency, respectively (Drolen and Smoot 2017). Both $U$ and $f$ can be driven by thermophysical conditions. If $L_{s}$ is not long enough, for a given OHP and evaporator-condenser configuration, the liquid slugs may not experience enough interaction with the evaporator to be effective. The vapor inertia limit is shown by

$Q_{\max }=\left(A N C_{N} r h_{f g}\left[\sigma \rho_{v} r\left(\cos \left(\theta_{r}\right)-\cos \left(\theta_{a}\right)\right)\right]^{1 / 2}\right) / \gamma$,

where $Q_{\max }$ is the net OHP heat transport capability based on inertial limit, $A$ is a scaling coefficient, $N$ is the number of channels, $C_{N}$ is the number of condensers, $h_{f g}$ is latent heat of vaporization, $\gamma$ is the evaporation fraction, and $\theta_{r}$ and $\theta_{a}$ are the receding and advancing fluid contact angles, respectively. Values for $A$ of 1.924 and 1.800 can be used for laminar and turbulent flow, respectively (Drolen and Smoot 2017).

Based on the vapor inertia and $L_{s}$ limits, OHP \#3 should continue to operate at increased temperatures when compared with its terrestrial performance, and results presented in this work confirm these expectations.

Figure 4 shows the configuration and instrumentation of OHP \#1, and Fig. 5 shows the same for OHPs \#2 and \#3. OHPs \#1 and \#2 are identical in construction and fill; however, they have differing boundary conditions, as shown in Figs. 4 and 5. OHP \#1 is heated in the center and cooled on both sides. OHP \#2 is heated in the center and cooled on only one side; the other side is supported by a thermally insulating G10 block. OHP \#3 has the same boundary conditions as OHP \#2; however, as previously mentioned, OHP \#3 is filled with R-134a rather than Butane.

Each OHP is instrumented with seven or eight RTDs and three types of patch heaters: two $25.4 \mathrm{~mm}$ x $50.8 \mathrm{~mm} 20 \mathrm{~W}$ polyimide heaters used together as the $40 \mathrm{~W}$ "large area" heater, one "small area" $12.7 \mathrm{~mm}$ x $12.7 \mathrm{~mm} 40 \mathrm{~W}$ ceramic heater, and one or two $45.7 \mathrm{~mm}$ x $12.7 \mathrm{~mm} 20 \mathrm{~W}$ polyimide startup heaters to assist with OHP startup, if necessary. To date, the startup heaters have never been used. The heater and RTD (numbered dot) configurations for each OHP are illustrated in Figs. 4 and 5 . The electronics box also houses a three-axis 
accelerometer to monitor and measure the on-orbit gravitational environment.
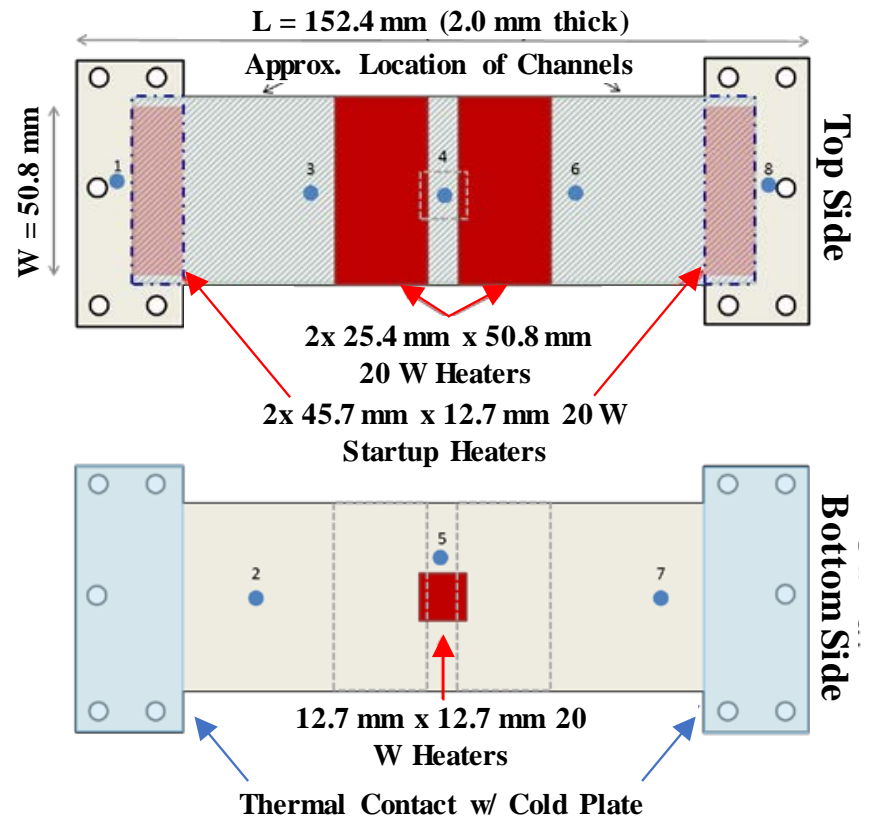

Fig. 4 Configuration and instrumentation of OHP \#1

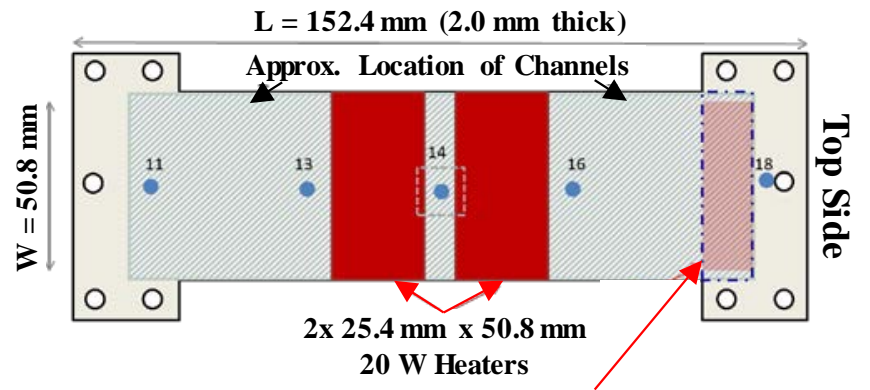

$45.7 \mathrm{~mm} \times 12.7 \mathrm{~mm} 20 \mathrm{~W}$

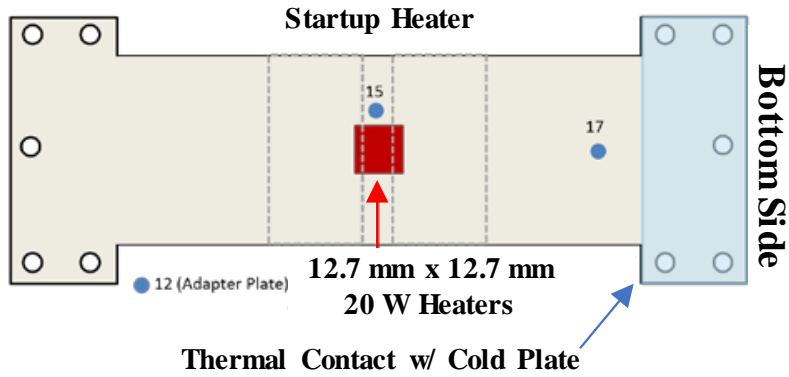

Fig. 5 Configuration and instrumentation of OHPs \#2 and \#3

\section{RESULTS}

Data collected during the first six months of on-orbit (OO) operations is presented here against the original ground truth (GT) data that was collected for the same OHPs as described in (Taft and Smith 2017). In the analysis of all test cases, experiments were categorized as either "Working" or "Not Working," denoting that the OHPs exhibited sustained steady oscillatory behavior or not, respectively. Table 1 gives the overall success rate (percentage of total test cases classified as "Working") for both GT and OO test series, where the total number of attempted experiments is indicated. Likewise, Table 2 breaks down the success rate for each operational configuration by test OHP-heater configuration, test series, and OHP power input, where "LA" and "SA" represent large area and small area heaters, respectively.
Table 1 Ground truth vs. on-orbit overall experiment success rate

\begin{tabular}{|l|l|}
\hline Test Series & $\begin{array}{l}\text { Success Rate } \\
\text { (Total Attempts) }\end{array}$ \\
\hline GT & $72 \%$ \\
& $(197)$ \\
\hline OO & $72 \%$ \\
& $(195)$ \\
\hline
\end{tabular}

Future work will perform an in-depth comparison of the ASETS-II data with the performance limits of oscillating heat pipes; however, a basic understanding of the model can be used to hypothesize the mechanism behind "Not Working" test cases. It is hypothesized that the "Not Working" ASETS-II data exhibits two different OHP operating limits: the $L_{s}$ limit and the vapor inertia limit (Drolen and Smoot 2017).

Given that OHP \#1 and OHP \#2 are identical except for the coldside boundary condition it seems likely that the "Not-Working" conditions seen on OHP \#2 large area heater test cases are the result of the $L_{s}$ limit. With one-sided cooling the distance between evaporator and condenser is more than doubled for half of the OHP. This hypothesis also applies to some OHP \#3 large are heater test cases.

OHP \#3 small area heater "Not-Working” test cases are most likely the result of the $B o$ limit. This OHP design and working fluid, R134a, were specifically chosen to exhibit the Bo limit in the 30-40 W input range.

The results presented in the remainder of this paper are based only on the successful, or "Working," test data.

Table 2 Ground truth vs. on-orbit experiment success rate breakdown

\begin{tabular}{|c|c|c|c|c|c|}
\hline \multirow{2}{*}{\multicolumn{2}{|c|}{ Configuration }} & \multicolumn{4}{|c|}{$\begin{array}{l}\text { Success Rate } \\
\text { (Total Attempts) }\end{array}$} \\
\hline & & $10 \mathrm{~W}$ & $20 \mathrm{~W}$ & $30 \mathrm{~W}$ & $40 \mathrm{~W}$ \\
\hline \multirow{2}{*}{ 1-LA } & GT & $\begin{array}{l}100 \% \\
(9)\end{array}$ & $\begin{array}{l}100 \% \\
(8)\end{array}$ & $\begin{array}{l}100 \% \\
(7)\end{array}$ & $\begin{array}{l}100 \% \\
(7)\end{array}$ \\
\hline & $\mathrm{OO}$ & $\begin{array}{l}100 \% \\
(8)\end{array}$ & $\begin{array}{l}100 \% \\
\text { (9) }\end{array}$ & $\begin{array}{l}100 \% \\
\text { (9) }\end{array}$ & $\begin{array}{l}100 \% \\
(6)\end{array}$ \\
\hline \multirow{2}{*}{$1-\mathrm{SA}$} & GT & $\begin{array}{l}100 \% \\
(9)\end{array}$ & $\begin{array}{l}100 \% \\
(7)\end{array}$ & $\begin{array}{l}100 \% \\
(6)\end{array}$ & $\begin{array}{l}100 \% \\
(7)\end{array}$ \\
\hline & $\mathrm{OO}$ & $\begin{array}{l}100 \% \\
(9)\end{array}$ & $\begin{array}{l}100 \% \\
(9)\end{array}$ & $\begin{array}{l}100 \% \\
(9)\end{array}$ & $\begin{array}{l}100 \% \\
(6)\end{array}$ \\
\hline \multirow{2}{*}{ 2-LA } & GT & $\begin{array}{l}89 \% \\
(9)\end{array}$ & $\begin{array}{l}100 \% \\
(7)\end{array}$ & $\begin{array}{l}86 \% \\
(7)\end{array}$ & $\begin{array}{l}86 \% \\
(7)\end{array}$ \\
\hline & $\mathrm{OO}$ & $\begin{array}{l}100 \% \\
(8)\end{array}$ & $\begin{array}{l}100 \% \\
(9)\end{array}$ & $\begin{array}{l}89 \% \\
(9) \\
\end{array}$ & $\begin{array}{l}17 \% \\
(6) \\
\end{array}$ \\
\hline \multirow{2}{*}{ 2-SA } & GT & $\begin{array}{l}100 \% \\
(9)\end{array}$ & $\begin{array}{l}100 \% \\
(6)\end{array}$ & $\begin{array}{l}100 \% \\
(6)\end{array}$ & $\begin{array}{l}100 \% \\
(6)\end{array}$ \\
\hline & $\mathrm{OO}$ & $\begin{array}{l}100 \% \\
(9)\end{array}$ & $\begin{array}{l}100 \% \\
(9)\end{array}$ & $\begin{array}{l}100 \% \\
(9)\end{array}$ & $\begin{array}{l}100 \% \\
(6)\end{array}$ \\
\hline \multirow{2}{*}{ 3-LA } & GT & $\begin{array}{l}22 \% \\
(9)\end{array}$ & $\begin{array}{l}0 \% \\
(8)\end{array}$ & $\begin{array}{l}0 \% \\
(7)\end{array}$ & $\begin{array}{l}0 \% \\
(7)\end{array}$ \\
\hline & $\mathrm{OO}$ & $\begin{array}{l}0 \% \\
(8)\end{array}$ & $\begin{array}{l}0 \% \\
(9)\end{array}$ & $\begin{array}{l}0 \% \\
(9)\end{array}$ & $\begin{array}{l}0 \% \\
(6)\end{array}$ \\
\hline \multirow{2}{*}{ 3-SA } & GT & $\begin{array}{l}100 \% \\
(13)\end{array}$ & $\begin{array}{l}62 \% \\
(13)\end{array}$ & $\begin{array}{l}21 \% \\
(14)\end{array}$ & $\begin{array}{l}22 \% \\
(9)\end{array}$ \\
\hline & $\mathrm{OO}$ & $\begin{array}{l}100 \% \\
(9)\end{array}$ & $\begin{array}{l}78 \% \\
(9)\end{array}$ & $\begin{array}{l}11 \% \\
(9)\end{array}$ & $\begin{array}{l}0 \% \\
(6)\end{array}$ \\
\hline
\end{tabular}

\subsection{Adapter Plate Temperature}

A study of the relationship between thermal resistance and adapter plate temperature has been made on each of the OHPs. A steady, fixed adapter plate temperature aboard the $\mathrm{X}$-37B is not guaranteed, therefore noticeable variation in the adapter plate temperature is observed. Figs. 6 through 8 show the results of thermal resistance with respect to adapter plate temperature for each OHP for both GT and OO test series, with respective heater types segregated. The error bars represent a 95\% 
confidence interval, corresponding to two standard deviations of the associated data point. GT adapter plate temperatures were controlled to vary over a possible temperature range predicted for flight, whereas the adapter plate for OO tests was not controlled.

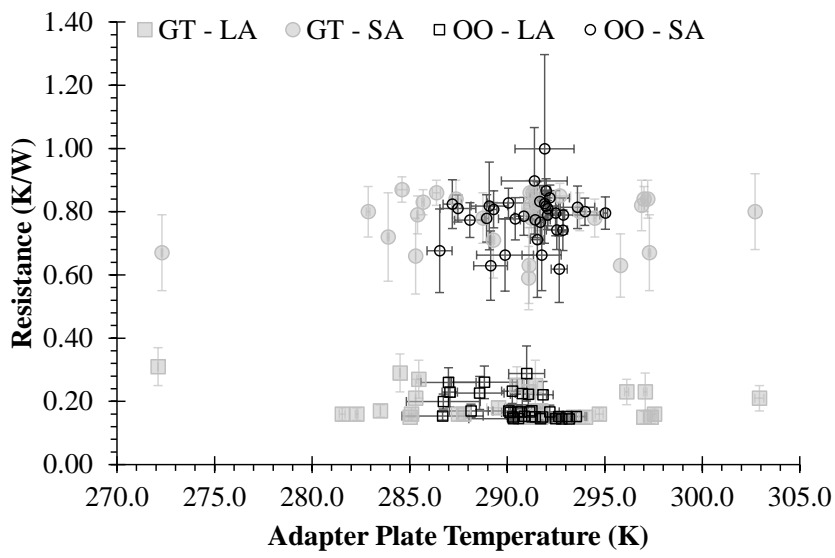

Fig. 6 OHP \#1 ground truth and on-orbit resistance vs. adapter plate temperature

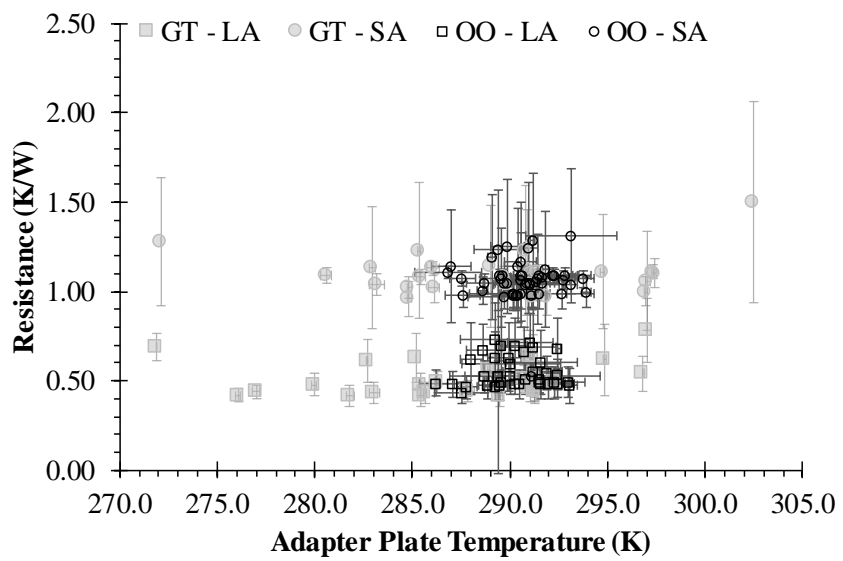

Fig. 7 OHP \#2 ground truth and on-orbit resistance vs. adapter plate temperature

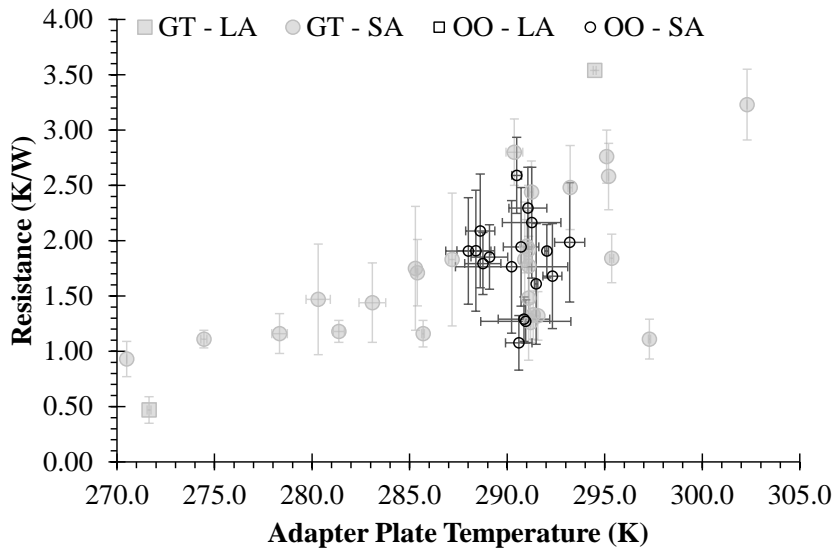

Fig. 8 OHP \#3 ground truth and on-orbit resistance vs. adapter plate temperature

The trends observed in Figs. 6 and 7 show that the performance of OHP \#1 and OHP \#2 does not appear to have any dependence on the adapter plate temperature, however, the performance of OHP \#3 exhibits a dependence on adapter plate temperature. The dependence observed in OHP \#3 may be primarily due to $L_{s}$ limit conditions, as described by Eq. (2), where the adapter plate temperature directly affects the liquid slugs' thermal condition, changing the critical $L_{s}$ for OHP performance. OHP \#3 was designed specifically to gain better insight into the OHP behavior at the boundaries of the Bo and $L_{s}$ limits, but the in-depth analysis of the related phenomena in those condition regions is ongoing and is not given in this publication.

\subsection{Hysteresis Effects}

A series of experiments was performed on the OHPs during flight to investigate possible hysteresis effects in the thermal resistance. For each OHP and heater, the power was cycled at $10 \mathrm{~W}$ increments from $10 \mathrm{~W}$ up to $40 \mathrm{~W}$ and back down to $10 \mathrm{~W}$ with a one-hour soak at each level and no cooling time between steps. Each of the OHP-heater configurations was cycled at three separate times. The hysteresis curves for all of the tests are shown in the Figs. 9 through 13. Error bars represent 95\% confidence intervals (two standard deviations), and no chart is shown for OHP \#3 with the large area heater because the OHP failed in each case.

Table 3 summarizes the hysteresis test results for both GT and OO, where resistance change from the beginning of the test to the end of the test is given. Changes that fall outside of the statistical uncertainty bounds (95\% confidence error bars) are shaded. Only one GT hysteresis power sweep was performed before launch.



Fig. 9 OHP \#1 on-orbit hysteresis resistance vs. power input with large area heater

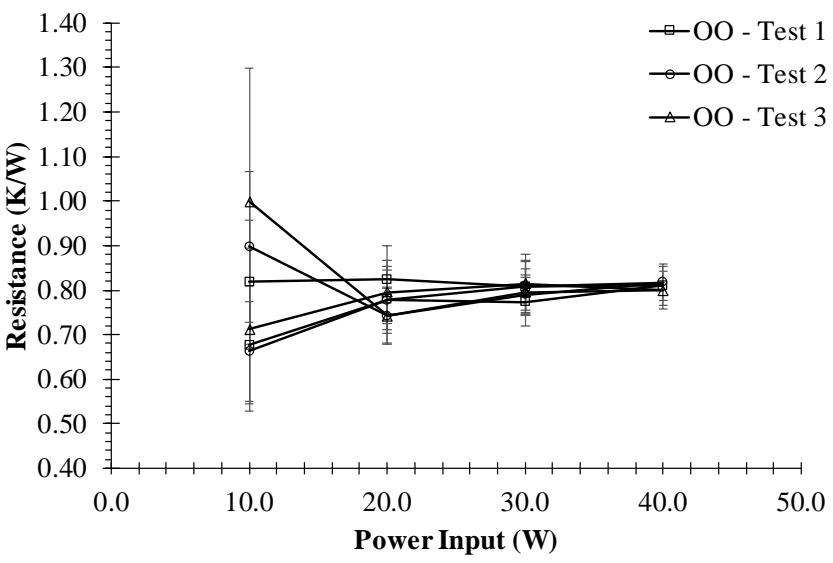

Fig. 10 OHP \#1 on-orbit hysteresis resistance vs. power input with small area heater

In general, whereas there is no clear trend of hysteresis effects in the OHPs, OHP \#3 exhibits somewhat erratic behavior, making a certain analysis extremely difficult. OHP \#3 was designed to operate at the edge of stability, to explore the operating limits, thus erratic behavior is expected. Although OHP \#1 with the small area heater 
shows some change for two of the three trials at the lowest power level, an inspection of the corresponding hysteresis chart suggests this may just be due to random behavior of the OHP, or, by inspecting the time series temperature trends in the OHP, it is likely this is just a byproduct of the difference in dynamic thermal environment experienced at the end of the hysteresis test versus the beginning.

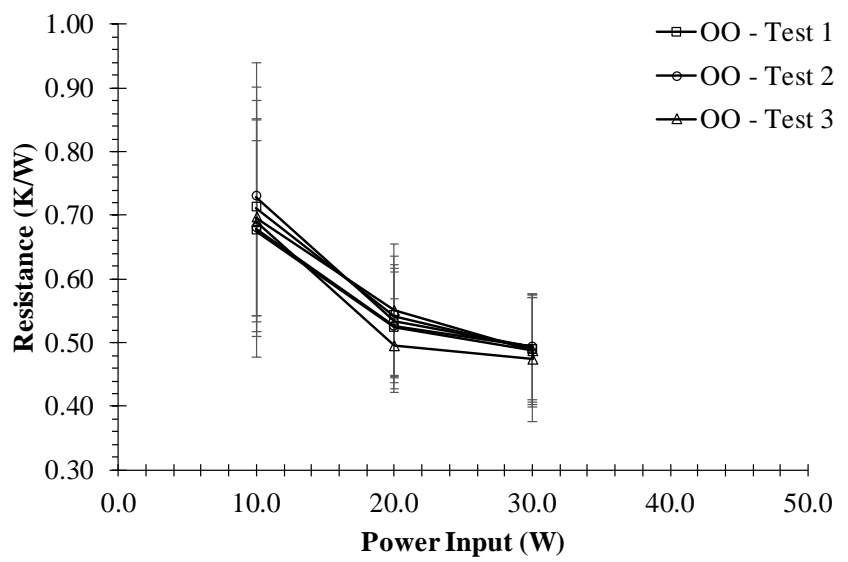

Fig. 11 OHP \#2 on-orbit hysteresis resistance vs. power input with large area heater

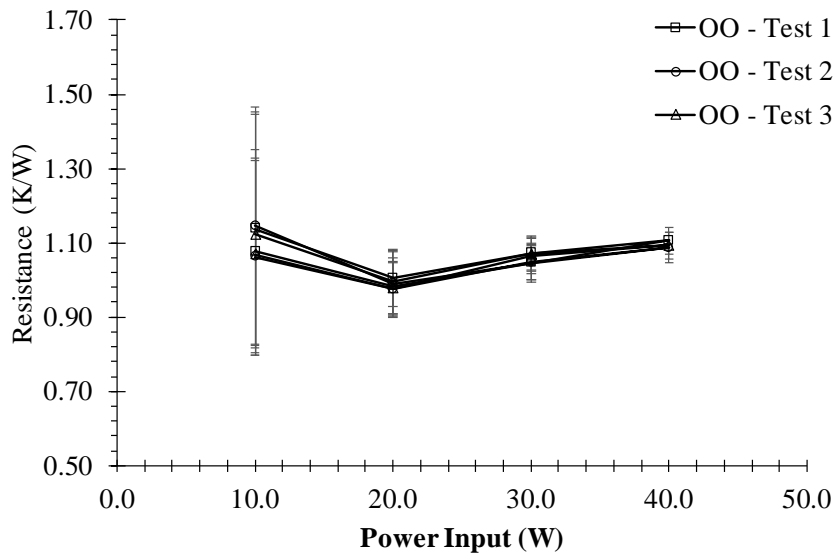

Fig. 12 OHP \#2 on-orbit hysteresis resistance vs. power input with small area heater

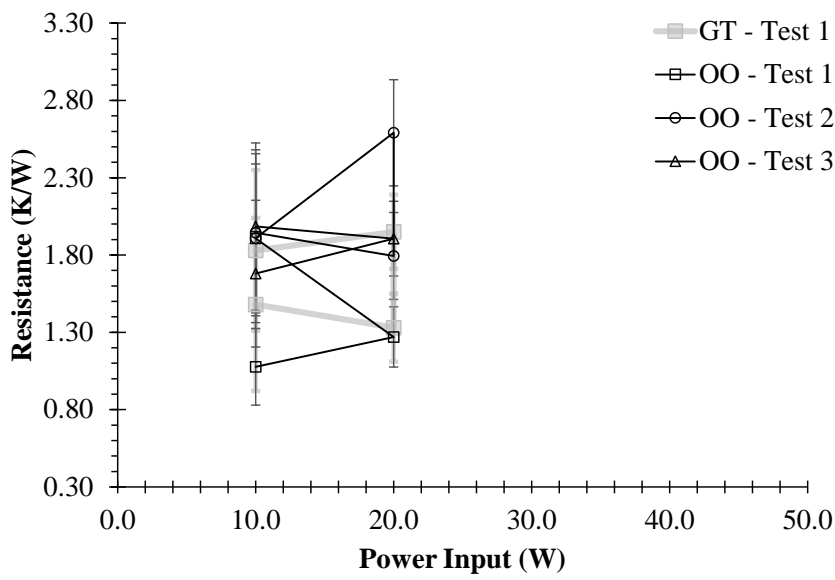

Fig. 13 OHP \#3 ground truth and on-orbit hysteresis resistance vs. power input with small area heater
Table 3 Ground truth and on-orbit hysteresis measurements summary

\begin{tabular}{|l|l|l|l|l|}
\hline \multirow{2}{*}{ Configuration } & \multicolumn{3}{l|}{$\begin{array}{l}\text { Resistance Change } \\
\text { (K/W) }\end{array}$} \\
\cline { 3 - 6 } & & Trial 1 & Trial 2 & Trial 3 \\
\hline 1-LA & OO & -0.01 & 0.01 & -0.07 \\
\hline 1-SA & OO & -0.14 & 0.23 & 0.29 \\
\hline 2-LA & OO & 0.04 & -0.05 & 0.01 \\
\hline 2-SA & OO & 0.06 & 0.08 & 0.05 \\
\hline 3-LA & OO & --- & --- & --- \\
\hline \multirow{2}{*}{ 3-SA } & GT & -0.35 & --- & --- \\
\cline { 2 - 5 } & OO & -0.83 & 0.03 & -0.31 \\
\hline
\end{tabular}

\subsection{Resistance vs. Power}

A general comparison is made of the thermal resistance performance with power between $\mathrm{OO}$ operation and GT operation of the OHPs. A compilation of 265 different test cases (including hysteresis tests) provided for characteristic evaluation of OO versus GT performance of the OHPs. Figures 14 through 16 show the thermal resistance for each OHP-heater configuration. The error bars represent +/- two standard deviations of the average values over all working experiment cases for the corresponding configuration, resulting in a 95\% confidence interval.

The results show no significant change in performance from GT to OO for OHP \#1 and \#2, but OHP \#3 exhibits an apparent slight increase in thermal resistance at the $30 \mathrm{~W}$ power level with the small area heater, where only one working data point was available for OO data. For OO cases, OHP \# 3 failed for each power level with the large area heater.

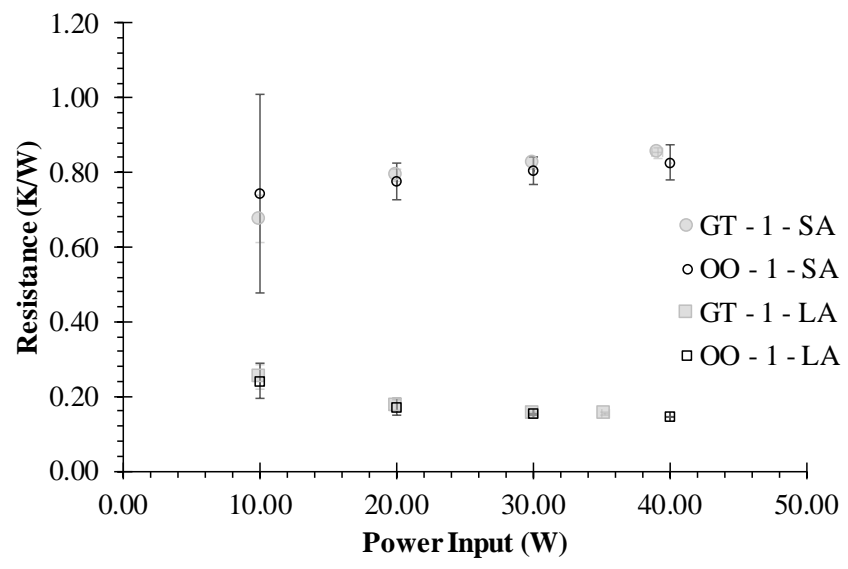

Fig. 14 OHP \#1 ground truth and on-orbit resistance vs. power input

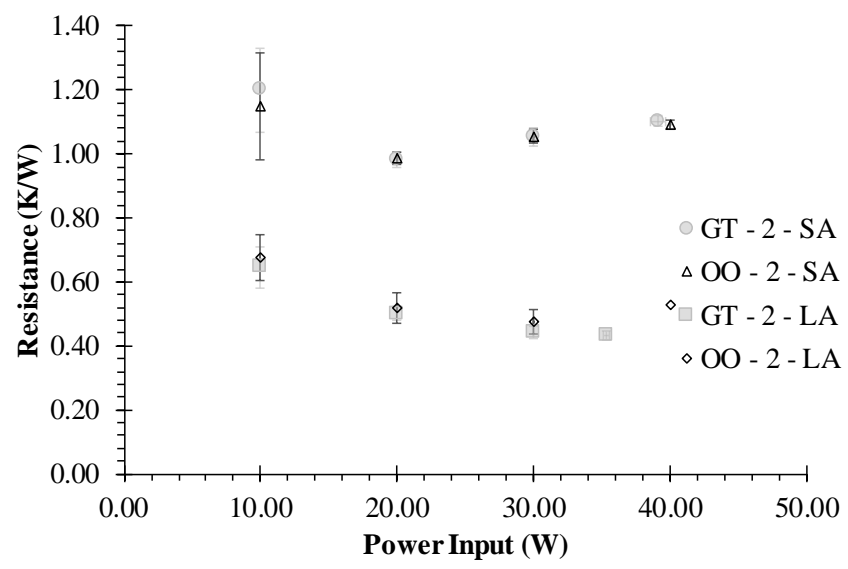

Fig. 15 OHP \#2 ground truth and on-orbit resistance vs. power input 


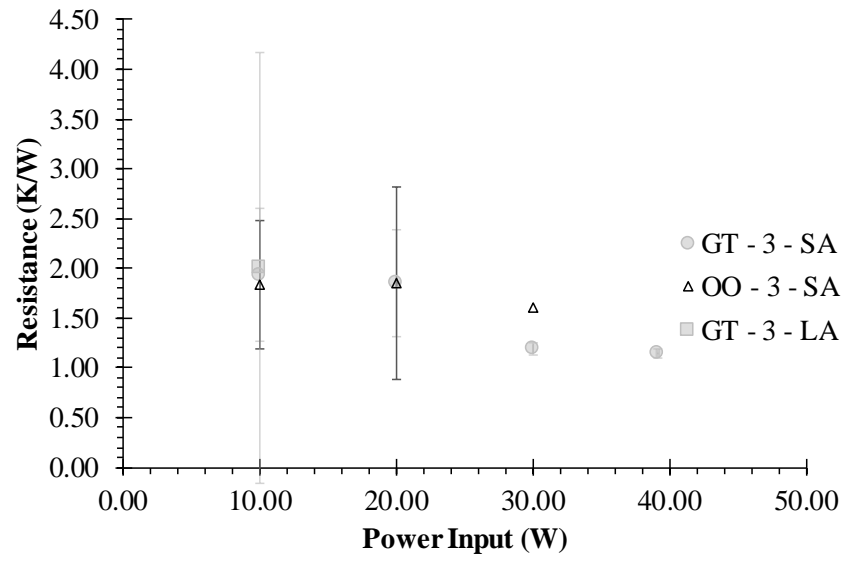

Fig. 16 OHP \#3 ground truth and on-orbit resistance vs. power input

\subsection{Operating Limits}

On-orbit operation of the OHPs near the $B o, L_{s}$ and vapor inertia limits was expected to change from GT experiments, given that the $B o$ is driven in part by gravitational forces, as found in Eq. (1), and that the other limits are thermophysically interdependent. Thus, an investigation into the $\mathrm{OO}$ performance of OHP \#3 near the operating limits was performed. Figures 17 and 18 show an overlay comparison of the evaporator temperatures and evaporator-condenser temperature differences, respectively, of OHP \#3 prior to onset of failure (indicated by oscillation termination in evaporator temperature data) for both GT and $\mathrm{OO}$ operations of the same OHP. Results from both the small area and large area heater are combined to form one plot.

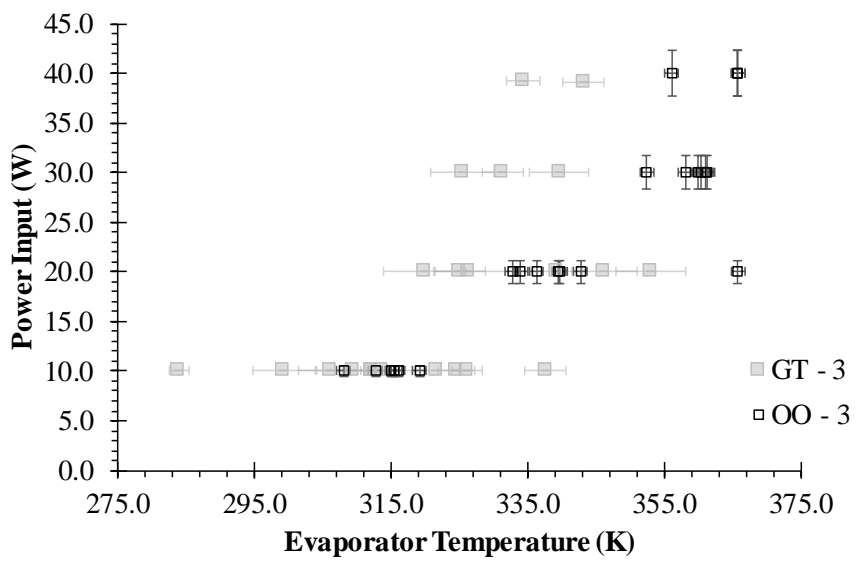

Fig. 17 Ground truth vs. on-orbit operating limit temperature analysis



Fig. 17 Ground truth vs. on-orbit operating limit temperature difference analysis
The maximum evaporator temperature for GT operation was approximately $356 \mathrm{~K}$. In the controlled testing of an identical OHP, the measured temperatures coinciding with the onset of the Bo limit on the ground were between $359 \mathrm{~K}$ and $364 \mathrm{~K}$, corresponding to Bo values of 5.8 and 7.5. The difference between the two results is small and may relate to instrumentation differences between the two tests (Drolen and Smoot 2017). The $356 \mathrm{~K}$ temperature corresponds to a $B o$ of 5.3, falling between the commonly accepted 3.4 to 4.0 upper limit for OHP operation and the recently proposed limit of 5.8 to 7.5 (Drolen and Smoot 2017). The OO test cases clearly demonstrate increased maximum evaporator temperature and evaporator-condenser temperature difference operation, with an increase to approximately 366 $\mathrm{K}$. For the $\mathrm{OO}$ test cases, operation likely ceases when the vapor inertia limit is reached. Further testing and data analysis need to be conducted to better separate the effects of the $L_{s}$, vapor inertia, and Bo limits on $\mathrm{OHP}$ operation. It is worth noting that test cases utilizing the large area heater may hit the $L_{s}$ limit prior to hitting the $B o$ limit.

\subsection{Long-Duration Performance}

In the first six months of orbit, OHP \#1 was tested under constant operation for a continuous six-week period. Figure 18 shows a tracking of OHP \#1's resistance performance with uncertainty over the full six weeks, where data was collected every 60 seconds. For this analysis, the large area heater was used at $20 \mathrm{~W}$. Over the testing period, OHP \#1 exhibited an average resistance of $0.17+/-0.02 \mathrm{~K} / \mathrm{W}$. For a comparison, the data given in Fig. 13 for OHP \#1 with the large area heater at $20 \mathrm{~W}$ is also $0.17+/-0.02 \mathrm{~K} / \mathrm{W}$. Long duration tests of the other OHPs and at different test configurations will be completed in the coming months.

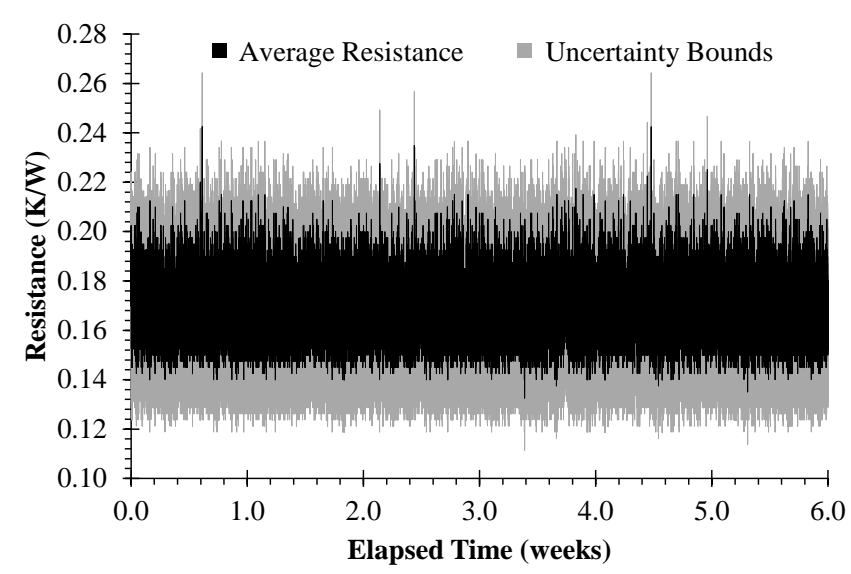

Fig. 18 OHP \#1 on-orbit long-duration resistance

\section{CONCLUSIONS}

Extensive data set analyses have been presented for three different OHPs comparing on-orbit data in microgravity aboard the X-37B to ground truth data. Each OHP performed as expected, where OO data for OHPs \#1 and \#2 mirrored GT performance, and the OHP \#3 OO maximum operating evaporator temperature increased from GT. It was shown that the OHPs experienced no significant hysteresis effects and performed successfully in six-week long continuous operation.

\section{NOMENCLATURE}

A scaling coefficient

Bo Bond number

$C_{N} \quad$ number of condensers

$f \quad$ nucleation frequency $\left(\mathrm{s}^{-1}\right)$

$g \quad$ acceleration due to gravity $\left(\mathrm{m} / \mathrm{s}^{2}\right)$

$h_{f g} \quad$ latent heat of vaporization $(\mathrm{J} / \mathrm{kg})$

$L_{s} \quad$ swept length (m) 
$N \quad$ number of channels

$Q_{\max } \quad$ maximum heat transport (W)

$r \quad$ hydraulic radius $(\mathrm{m})$

$U \quad$ fluid velocity $(\mathrm{m} / \mathrm{s})$

\section{Greek Symbols}

$\gamma \quad$ evaporation fraction

$\rho_{l} \quad$ liquid mass density $\left(\mathrm{kg} / \mathrm{m}^{3}\right)$

$\rho_{v} \quad$ vapor mass density $\left(\mathrm{kg} / \mathrm{m}^{3}\right)$

$\sigma \quad$ surface tension $(\mathrm{N} / \mathrm{m})$

$\theta_{a} \quad$ advancing contact angle (deg)

$\theta_{r} \quad$ receding contact angle (deg)

\section{REFERENCES}

Akachi, H, 1990, U.S. Patent Application for a "Structure of a heat pipe,” Patent No. US4921041A, filed 25 June 1988, published 1 May 1990.

Drolen, B. L., and Smoot, C. D., 2017, "Performance Limits of Oscillating Heat Pipes: Theory and Validation," Journal of Thermophysics and Heat Transfer, 31(4), 920-936. http://dx.doi.org/10.2514/1.T5105

Laun, F. F. and Taft, B. S., 2014, "Experimental Investigation of In Situ Pressure Measurement of an Oscillating Heat Pipe," Frontiers in Heat Pipes, 5(8).

http://dx.doi.org/10.5098/fhp.5.8
Ma, H., 2015, Oscillating Heat Pipes, Springer, New York, NY.

Smith, S. M., Taft, B. S., Moulton, J., 2014, "Contact Angle Measurement for Advanced Thermal Management Technologies," Frontiers in Heat and Mass Transfer, 5(6). http://dx.doi.org/10.5098/fhp.5.8

Taft, B. S., Williams, A. D., and Drolen, B. L., 2012, "Review of Pulsating Heat Pipe Working Fluid Selection", Journal of Thermophysics and Heat Transfer, 26(4), 651-656. https://dx.doi.org/10.2514/1.T3768

Taft, B., 2013, "Non-Condensable Gases and Oscillating Heat Pipe Operation," Frontiers in Heat Pipes, 4(1). http://dx.doi.org/10.5098/fhp.v4.1.3003

Taft, B. S., Laun, F. F., Smith, S. M., and Hengeveld, D. W., 2015, "Microgravity Performance of a Structurally Embedded Oscillating Heat Pipe," Journal of Thermophysics and Heat Transfer, 29(6), 329337. http://dx.doi.org/10.2514/1.T4151

Taft, B., 2017, "Space Vehicles Directorate Thermal Systems Roadmap," Proceedings of the Spacecraft Thermal Control Workshop 2017, The Aerospace Corporation, El Segundo, CA.

Taft, B. S., and Smith, S. M., 2017, “ASETS-II Oscillating Heat Pipe Space Flight Experiment: Ground Truth Results,” ASME 2017 Summer Heat Transfer Conference, HT2017-4706, Bellevue, Washington. 